\title{
Ecos Labanianos na Pedagogia Dançante de Eva Schul
}

\author{
Fellipe Santos Resende \\ Universidade Federal do Rio Grande do Sul - UFRGS, Porto Alegre/RS, Brasil \\ E-mail: fellipe-resende@hotmail.com \\ Suzane Weber da Silva \\ Universidade Federal do Rio Grande do Sul - UFRGS, Porto Alegre/RS, Brasil \\ E-mail: ssuzaneweber@gmail.com
}

\section{Resumo}

Este artigo busca trazer a noção de ecos labanianos a partir de elementos técnicos presentes nas aulas de dança contemporânea de Eva Schul, considerando aspectos relacionados à filiação de movimento de Rudolf Laban que alcançam Eva Schul através de Hanya Holm e Irmgard Bartenieff. Seu delineamento metodológico inclui observação e prática regular das aulas de Schul, entrevista semiestruturada com a mesma, descrição e contextualização imagética de elementos presentes em suas aulas, e uso de contribuições teóricas que os respaldam. Exemplos de elementos que corporificam ecos labanianos nas aulas de Schul são: trabalho de chão, seis posições do vocabulário moderno e pêndulos (a partir de Holm); suporte muscular interno, conexões ósseas, homo e contralateralidade, metade do corpo, queda de joelhos, círculo de braços e propulsão de pelve (a partir de Bartenieff). Tendo sido constantemente reelaborado e difundido por diferentes figuras, o legado de Laban chega em Schul gerando ecos em suas aulas, cenário de significativa potência poética e histórica quanto à transmissibilidade de conhecimentos incorporados, e atualização de pensamentos e práticas numa pedagogia dançante contemporânea.
This article seeks to bring the notion of labanian echoes from technical elements present in Eva Schul's contemporary dance classes, considering aspects related to the movement affiliation of Rudolf Laban that reach Eva Schul through Hanya Holm and Irmgard Bartenieff. Its methodological design includes observation, regular practice of Schul's classes, semi-structured interview with her, description and imagery contextualization of elements present in her classes, and use of theoretical contributions that support them. Examples of elements that embody labanian echoes in Schul's classes: floorwork, six modern vocabulary positions and pendulums (from Holm); core muscle support, bonny connections, homo and contralaterality, body-half, knee drop, arm circles and pelvic propulsion (from Bartenieff). Since it has been re-elaborated and disseminated by different figures, Laban's legacy reaches Schul generating echoes in her classes, a scenario of significant poetic and historical potency, regarding the transmissibility of incorporated knowledge, and updating of thoughts and practices into a contemporary dance pedagogy. 
Este artigo busca trazer a noção de ecos labanianos a partir de elementos técnicos ${ }^{1}$ presentes nas aulas de dança contemporânea de Eva Schul (1948). São considerados aspectos relacionados à filiação de movimento de Rudolf Laban (18791958), que alcançam Eva Schul através de Hanya Holm (1893-1992) e Irmgard Bartenieff (1900-1981).

Se tratando de pedagogias para corpos dançantes, as aulas de dança são trazidas como nosso pano de fundo, entendidas como práticas corporais formativas e espaços para construção de saberes, que permeiam tanto os vocabulários-corpo de quem as conduz quanto de quem as apreende.

Construindo estilos pedagógicos e estruturas de ensino a partir de suas trajetórias, as mestras e mestres constituem-se como referências de base para seus discípulos, formando-os como corpos dançantes. Embora os mestres de dança formem de maneira geral uma "descendência", muitos bailarinos não se limitam a seguir os postulados do contexto formativo em que estiveram inseridos, iniciando outras pesquisas sobre o movimento e inaugurando novas maneiras de se dançar e de se pensar a dança (DANTAS, 1999).

Ainda que esta nomenclatura - mestres e discípulos - tenha sido ampliada e ganhado alternativas, nosso imaginário não deixa de ser povoado pela figura e importância do legado das mestras e mestres, professoras e professores de dança, cujas práticas corporais constituem nossos repertórios e tecem nossos saberes incorporados.

É, pois, reconhecendo a grandeza e importância de uma destas figuras, Rudolf Laban (figura 1), referência da dança moderna alemã no seio do

1 Tal termo é respaldado pelo conceito de técnica corporal, que despontou em 1934 através da famosa obra Sociologia e Antropologia do francês Marcel Mauss, e que compreende "as maneiras pelas quais os homens, de sociedade a sociedade, de uma forma tradicional, sabem servir-se de seus corpos" (MAUSS, 1974, p. 401). No campo das Artes Cênicas as técnicas podem ser entendidas como partes integrantes de um sujeito, e não de modo externo ou alheio a ele (STRAZZACAPPA, 2012), pois aquilo que se aprende corporalmente se torna parte de sua inteligência (HACKNEY, 2003), um saber incorporado (RESENDE, 2018). movimento expressionista, como construtor de um legado cuja influência reverbera e está presente em muitas práticas da contemporaneidade, no campo das artes, terapias e dos estudos do movimento como um todo (ALMEIDA, 2017), que buscamos aqui identificar rastros desse legado. Desse modo, somamos nossas vozes e experiências enquanto autores e corpos que dançam sob o farol de Eva Schul para apresentar neste artigo a noção de ecos labanianos, a partir de elementos técnicos identificados nas aulas de dança contemporânea de Schul (figura 2), professora e coreógrafa, referência regional e nacional da dança brasileira, atuante de maneira mais contínua desde a década de noventa na capital gaúcha, Porto Alegre/RS.

Figura 1 - Rudolf Laban.

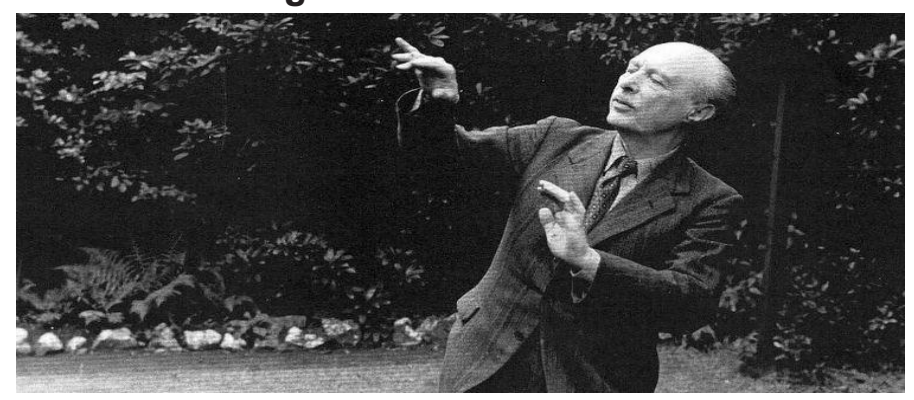

Fonte: Emove Institute ${ }^{2}$

Figura 2 - Eva Schul.

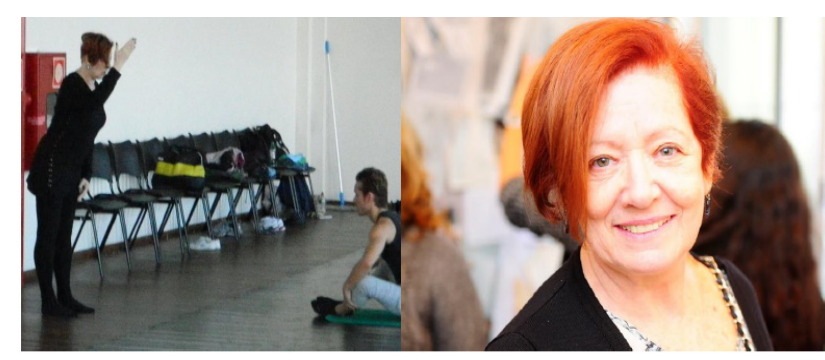

Fontes: Coletivo de Dança Sala 209 e Revista Donna ${ }^{3}$.

2 Disponível em: https://www.emoveinstitute.com/wp-content/uploads/2018/12/thumbnail-2.jpg. Acesso em: 01 abr. 2019.

3 Disponíveis em: https://www.facebook.com/pg/ColetivoDeDancaSala209/photos/. Acesso em: 01 set. 2016; e http://revistadonna.clicrbs.com.br/premio-donna/premio-donna-mulheres-que-inspiram-eva-schul/. Acesso em: 25 ago. 2017. 
O corrente estudo desdobra-se da dissertação de mestrado intitulada "Enrola um, dois, três até a cintura...": princípios organizativos de movimento nas aulas de dança contemporânea de Eva Schul (RESENDE, 2018), elaborada no Programa de Pós-graduação em Artes Cênicas da UFRGS. Seu delineamento metodológico inclui observação, prática regular das aulas de dança contemporânea de Eva Schul, entrevista semiestruturada com a mesma, descrição e contextualização imagética de elementos das referidas aulas, e uso de contribuições teóricas sobre figuras de vertentes modernas e somáticas ${ }^{4}$ da dança que os respaldam, haja visto a presença expressiva de vocabulário moderno e exercícios com abordagem mais perceptiva e sensível nas aulas de Schul.

\section{Disparador de ecos:} Laban como ponto de partida

Parte-se do precioso legado de Laban para a dança de modo a identificar especificidades que foram intermediadas por Holm e Bartenieff e que são atualizadas em Schul. Tais traços seguem vivos nas diferentes gerações de bailarinos que cruzaram por Schul, em suas mais de cinco décadas de docência em dança.

Os ecos a serem apontados situam-se como desdobramentos paralelos a tudo o que já se entende como dado no campo de contribuições gerais de Laban. Neste contexto, a aposta no desenvolvimento de um sentido da dança como fator formativo do ser humano (NAVAS; DIAS, 1992), uma metodologia que ensina o corpo dançante a responder a diferentes exigências e solicitações (DANTAS; WEBER, 2017), e condutas como pesquisar movimentos por meio de improvisações, usar vários tipos de dança em uma coreografia, entre outras características (LABAN, 1978), são pensamentos e práticas que reverberam ainda hoje em muitas pedagogias dançantes, sugerindo o

4 O termo somática respalda técnicas e métodos educacionais de conscientização corporal que se concentram no campo da Educação Somática, originado no século XX (VIEIRA, 2015), dentre os quais podemos citar os Bartenieff Fundamentals, com os quais Eva Schul teve contato formativo em períodos que residiu nos EUA. que Rengel (2004) denomina como um prenúncio labaniano da perspectiva contemporânea na dança.

O sistema para análise e notação de movimentos criado por Laban se tornou uma de suas assinaturas e seguiu vivo, recebendo colaborações posteriores de inúmeras discípulas ${ }^{5}$ (FERNANDES, 2006). Dentre estas figuras colaboradoras está a alemã Irmgard Bartenieff (figura 3), que difundiu na América do Norte o Sistema Laban/Bartenieff de Análise do Movimento (Laban/Bartenieff movementanalysis LBMA), sendo uma figura-chave na formação de Eva Schul, especialmente como referência de elementos somáticos e conectividade do corpo em seu entorno.

Figura 3 - Irmgard Bartenieff.

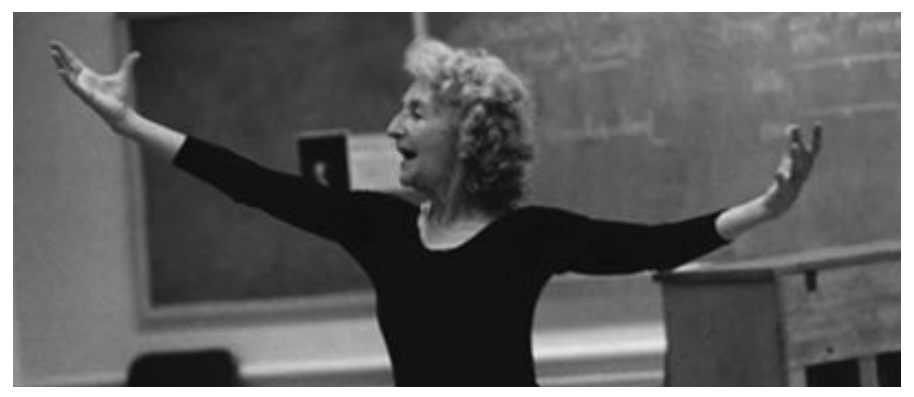

Fonte: Laban/Bartenieff Institute of Movement Studies ${ }^{6}$.

Contemporâneo à maioria dos movimentos que compuseram as chamadas vanguardas históricas que marcaram o início do século $X X$, as pesquisas de Laban tiveram grande contribuição de dois mestres considerados precursores desses movimentos: o pedagogo e artista francês François Delsarte (1811 - 1871), cujo legado Laban pôde conhecer através de treinamento com um de seus ex-discípulos; e o

$5 \mathrm{~A}$ influência de Laban é muito forte inclusive entre pesquisadoras brasileiras, havendo em todo o país uma série de docentes, artistas, terapeutas, entre outros, com formação em Laban através de diferentes escolas. No Rio Grande do Sul destacam-se Flávia Pila do Valle, Cibele Sastre e Juliana Vicari. Para melhor acompanhar a Arte do Movimento, Pesquisa e Genealogia da práxis de Laban no Brasil, ver Melina Scialom (2017).

6 Disponível em: https://labaninstitute.org/resources/media-gallery/. Acesso em: 01 abr. 2019. 
pedagogo e compositor suíço Émile-Jacques Dalcroze (1865 - 1950), com quem teve contato direto no período em que desenvolveu seu trabalho na Alemanha (MOTA, 2012). Delsarte, mesmo não sendo bailarino, sabia observar e analisar o movimento com meticulosidade, não apenas em suas características motoras, mas na sua natureza emocional (SILVA, 2005), acreditando que o mesmo atingia sua máxima eficiência com o mínimo esforço (GIGUERE, 2016).

É importante exemplificar que esta noção de mínimo esforço seguiu adiante com Laban e mostrou-se presente nos estudos que desenvolveu, sendo o peso um dos fatores de movimento que organizava suas análises e conteúdos teóricos, ao lado do fluxo, espaço e tempo (LABAN, 1978). Muitas estratégias pedagógicas influenciadas por Laban usaram estes quatro fatores, bem como as qualidades de movimento que contemplam, em suas concepções de movimento e formação em dança. Tal estrutura reverberou no trabalho de artistas e docentes que se valeram e se valem desse conhecimento, como é o caso de Eva Schul e dois dos princípios organizativos de movimento presentes em sua técnica: estudo do peso e do esforço mínimo, e estudo do fluxo e da qualidade de fluência, os quais norteiam, junto a outras diretrizes, a dinâmica de esforços e ações durante as aulas e conferem parte de sua assinatura estética e pedagógica (RESENDE, 2018; RESENDE; SILVA, 2019).

Em Dalcroze, Laban pôde encontrar a Eurritmia, um sistema de preparação muscular e rítmica a fim de conectar o senso rítmico a uma educação corporal. Tanto Delsarte quando Dalcroze trouxeram contribuições marcantes para a história da dança ocidental como um todo e, direta ou indiretamente, contaminaram grandes nomes precursores da dança moderna, tanto na escola americana quanto na alemã, tais como Isadora Duncan, Ruth Saint-Denis, Ted Shawn, Mary Wigman, Doris Humphrey, Martha Graham, Merce Cunningham, Hanya Holm, Kurt Jooss, Alwin Nikolais, Susanne Linke e Pina Bausch (TOURINHO; SILVA, 2006; NEVES, 2010).

Resultado das influências modernistas de seu tempo, o trabalho labaniano também reverberou di- retamente em muitas destas figuras da dança, com destaque para Mary Wigman (1886-1973), bailarina, coreógrafa e professora alemã que se tornou uma das matrizes da dança expressionista alemã (NAVAS; DIAS, 1992). Tendo sua trajetória ligada aos ensinamentos de Laban, Wigman foi sua aluna e colaboradora, mas reagiu violentamente contra seus princípios, criando em 1920 um centro de estudos próprio (INFANTE, 2011), sendo responsável por parte da formação de artistas conterrâneas como Dore Hoyer, Susanne Linke, e Hanya Holm (figura 4) - também figura-chave na formação de Eva Schul.

\section{Figura 4 - Hanya Holm.}

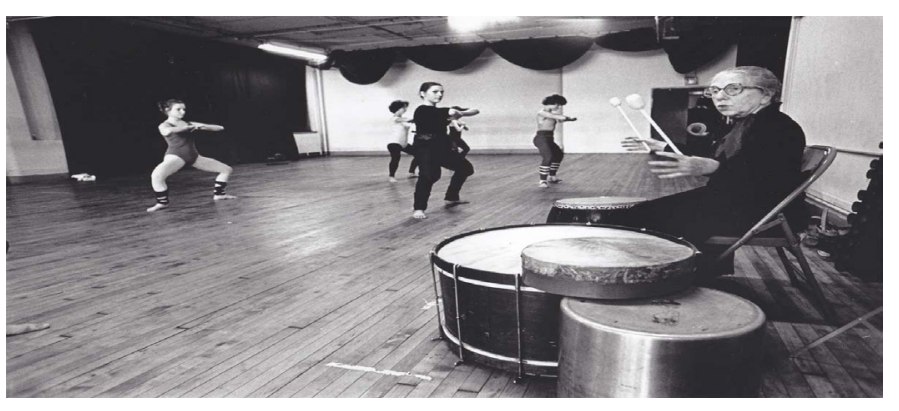

Fonte: Foto por Patrick Berthelot ${ }^{7}$.

As noções construídas por Laban tiveram forte ressonância nas técnicas corporais como um todo, reverberando ainda em figuras como a de seu colaborador e discípulo Kurt Jooss, e no coreógrafo norte-americano Alwin Nikolais (1910-1993), que recebeu suas influências através da mestra Hanya Holm, discípula, por sua vez, de Mary Wigman. Cabe destacar brevemente que Nikolais também foi muito importante na formação de Eva Schul. Um artista plural e com atuações em dança, artes plásticas e elementos de cenografia, Nikolais também desenvolveu sua pedagogia própria, apreendendo muito do que viveu com as mestras modernas Martha Graham, Doris Humphrey e Hanya Holm: a mais marcante e de quem foi assistente (NAVAS; DIAS, 1992; CAVRELL, 2015).

Para enxergar essas várias relações sendo tecidas e ampliadas em outros espaços e tempos,

7 Disponível em: http://bearnstowjournal.org/historicalphotos.htm. Acesso em 18 mai. 2018. 
buscamos a visualidade de um mapa-múndi, com ecos difusos a partir de ações de um protagonista: Laban. Como veremos a seguir, através de Holm e Bartenieff algumas interferências chegaram no fazer dança de Eva Schul. Um cenário singular de potência histórica, pedagógica e poética.

\section{Intermediação de ecos: Holm e Bartenieff}

Bailarina, coreógrafa e professora de dança (SORELL, 1969), Hanya Holm teve seu trabalho intimamente relacionado ao de Laban e Wigman. Em sua infância estudou no Dalcroze Institute e na década de vinte ingressou na companhia de Mary Wigman, na qual permaneceu por dez anos, sendo sua maior discípula, e se tornando instrutora-chefe e codiretora de sua escola em Dresden, na Alemanha. Incorporando pensamentos importantes de sua mestra, Holm veio a ser a sucessão mais direta de Wigman nos EUA, mudando-se para Nova York em 1931 para dirigir a American Wigman School (ENCYCLOPEDIA OF WORLD BIOGRAPHY, 2010; LAMBERT, 2016).

Ao perceber que o expressionismo germânico não se encaixava mais com os anseios da juventude norte-americana, suas visões sobre ensino a colocaram em desacordo com Wigman, já que num cenário cultural diferente desejava modificar a técnica para se adaptar aos alunos americanos que lá estudavam (GIGUERE, 2016). Além disso, a atenção de Wigman às políticas da pré-Segunda Guerra Mundial, inclusive sua controversa afinidade com o movimento nazista, era desagradável à Holm e à presença de seus bailarinos judeus. Desse modo, alguns princípios da técnica de Wigman foram mantidos nas aulas, mas houve um redirecionamento das estratégias adotadas frente às características comportamentais e físicas dos americanos (NORA, 2013).

Em 1936, após seu nome ser desvinculado completamente da escola de Wigman, surge a Hanya Holm School of Dance, momento em que mais distanciada de suas fontes Holm conduz seu estúdio e cultiva habilidades que a levaram a desenvolver sua própria técnica, influenciando vários bai- larinos nos EUA (LAMBERT, 2016; GIGUERE, 2016).

Dentre os conceitos explorados por Holm destacam-se a descentralização e não hierarquia entre o corpo e suas partes, a partir da premissa de que o fluxo do movimento se coordena com o fluxo da vida (DANTAS, 2013), noções importantes para a pedagogia de Schul, e que remetem à valorização labaniana do fluxo e do espaço como fatores importantes do movimento.

Irmgard Bartenieff, por sua vez, foi uma bailarina, educadora somática, pioneira da dançaterapia, estudiosa do movimento, discípula de Rudolf Laban (tendo o conhecido em 1925, em Berlim), e fisioterapeuta pela New York University/EUA (SFOGGIA, 2013, CAETANO, 2015). Embasada na investigação do material de Laban, deu andamento a seus próprios interesses de estudo sobre a linguagem do movimento, integrando sua formação como fisioterapeuta ao sistema de análise de movimento labaniano (SASTRE, 2017). Orientada pela ação e guiada pela palavra-chave conexão (HACKNEY, 2003) a principal colaboração de Bartenieff ao referido sistema foi o desenvolvimento da Categoria Corpo (o que movemos?), em conjunto às outras categorias existentes: Expressividade (como movemos?), Forma (com quem nos movemos?) e Espaço (onde nos movemos?) (SFOGGIA, 2013).

Paralelamente à sua atividade em instituições hospitalares, Bartenieff manteve-se em interação com a Dança, introduzindo a Labanotação (integrante do LBMA) em Nova York, acolhida por Hanya Holm em seu estúdio (LAMBERT, 2016).O método desenvolvido com seus pacientes de poliomielite tornou-se a base dos Bartenieff Fundamentals (BF), uma abordagem para reeducar o corpo, que desenvolve a eficiência e a expressão do movimento (VALLE, 2005), e que propõe uma experiência senso-cinestésica e cognitiva, levando em conta a totalidade do corpo, assim como a conectividade dos movimentos (CAETANO, 2015).

Dentre traços pedagógicos que se destacam está a noção de conectividade e a relação do sujeito com seu entorno, em "encontro e intersecção com o am- 
biente" (LAMBERT, 2016, p. 51), ressonando a ideia de fluxo e integralidade presente em Holm, ecoando Laban, e agregando valor conceitual e prático às proposições de Schul em suas aulas de dança e criações.

\section{Schul em cena: incorporação de princípios na construção de um fazer próprio}

Tendo se dedicado primeiramente ao ballet desde que se mudou para Porto Alegre com os pais em 1956 até 1964, Eva Schul descobre a dança moderna por meio do $1^{\circ}$ Congresso da Dança Clássica do Brasil, em Curitiba/PR, em 1960. Ainda assim, muda-se para os EUA em 1964, estagiando no New York City Ballet por um ano. Ao retornar para Porto Alegre continua a estudar ballet com Tony Petzhold, figura pioneira da dança no Rio Grande do Sul (HELDEN; FREIRE, 2002).

No início dos anos setenta, retoma o interesse pela dança moderna instigado no Congresso em Curitiba, viajando para Montevidéu, no Uruguai, onde estuda dança moderna com Elsa Vallarino e princípios da análise do movimento de Laban com Hebe Rosa. Em Buenos Aires, na Argentina, por sua vez, estudou a técnica de dança moderna de Martha Graham com Renate Schottelius e Ana Itelman (DANTAS, 2013).

De volta ao Brasil, assiste em 1975, em Porto Alegre, um espetáculo da Nikolais Dance Theatre, companhia dirigida pelo mestre norte-americano Alwin Nikolais, com quem já tinha feito um curso de verão nos EUA. No mesmo período, Nikolais conhece o trabalho que Schul estava desenvolvendo em seu estúdio, e a incentiva a se mudar para Nova York. Eva relata sobre este contexto:

Eu resolvi ir pros Estados Unidos fazer um curso de férias, de verão. $\mathrm{E}$ descobri o $\mathrm{Ni}$ kolais. Fiz o verão todo com ele. Ele dava cursos intensivos tipo os que eu dou, só que de três, quatro horas diárias. E quando eu voltei (ao Brasil), continuei fazendo o que eu fazia, já mais incrementado, já com alguma base técnica. Em setenta e cinco o Nikolais veio se apresentar, e eu falei pra ele "vem ver o que eu tô fazendo, me diz se eu enlouqueci". Ele disse "vamo embo- ra, vem comigo". Eu fui embora na hora, porque ele deu o aval para o que eu tava experimentando. (SCHUL, 2017b, n.p).

Eva Schul passa então a estudar com $\mathrm{Ni}$ kolais, mas principalmente com Holm. Em outros lugares da cidade estuda ainda improvisação e composição coreográfica, conscientização do movimento e o sistema Laban (DANTAS, 2013; SOARES, 2014). Entre as idas e vindas ao Brasil, entre as décadas de setenta e noventa, Schul vivencia ainda práticas corporais com Bartenieff, tanto de maneira direta, quanto com seus discípulos.

Com toda sua bagagem e vivências, Schul legou contribuições muito importantes na Região Sul como um todo, tendo contribuído na década de oitenta para a criação dos cursos superiores de Dança e Teatro na Pontifícia Universidade Católica do Paraná (PUC/ $\mathrm{PR}$ ) e integrado seu corpo docente, o que a permitiu instrumentalizar os conhecimentos que incorporou nos EUA numa pedagogia muito próxima a de suas mestras, especialmente a de Holm. Na década de noventa, por sua vez, retorna a Porto Alegre, e em 1991 funda a Ânima Cia. de Dança, produzindo diversas obras e construindo traços próprios de sua poética.

Influenciando gerações de bailarinos que buscavam uma formação alternativa à linha clássica (DANTAS, 2013), os ensinamentos e conhecimentos de Schul ultrapassaram os limites da capital, estendendo-se a diversas cidades gaúchas (NORA, 2013), panorama sobre o qual Schul dá o seguinte relato:

É muito orgulho [ter formado gerações de artistas, de coreógrafos, de pessoas que estão fazendo a diferença na dança]. Eu acho que nada me realizou mais do que ser professora. Porque, mesmo como coreógrafa, eu fui professora, e o fato de ter sempre alimentado essa participação dos bailarinos fez com que eles aprendessem a ser criadores. Fez com que eles aprendessem que criar não é repetir aquilo que eles conhecem. [...] Faz muita diferença que cada um desses coreógrafos esteja caminhando com suas próprias pernas em busca de algo muito mais inovador do que aquilo que aprendeu comigo. Não tem recompensa maior. (SANTOS, 2004, n.p). 
Semelhante à Holm, que precisou reinventar sua dança adaptando-a à cultura estadunidense, Eva Schul teve a necessidade de recriar os princípios técnicos e pedagógicos assimilados nos EUA à maneira de se mover, pensar e viver no sul do Brasil (DANTAS, 2013), processo sobre o qual ela conta:

Quando eu voltei pro Brasil [...] eu tinha muito material pra selecionar, muitas experiências diferentes, muito conteúdo. Então eu tinha só que organizar pra um novo mundo, um novo corpo, um novo espírito. O corpo americano é completamente diferente do corpo brasileiro. A velocidade americana é completamente diferente da velocidade brasileira. (SCHUL, 2017a, n.p).

Quanto à importância de Holm e Bartenieff, por sua vez, Schul pontua:

Hanya [...] foi a pessoa que realmente me ensinou tudo que eu sei hoje. E paralelo à Hanya a Bartenieff, que eram duas figuras que vinham de um outro mundo, que não era nem o planeta americano em que eu trabalhei com Graham, com Cunningham, com Limón, com todos eles. Todos me deram alguma coisa, mas ninguém me deu o essencial. Essas duas germânicas me deram o essencial. Porque elas vinham do planeta experimentação, elas nunca mostraram um único movimento, elas só falavam, elas faziam a gente desenvolver o cérebro. [...] Essas duas pessoas foram as mais marcantes na minha vida com certeza. (SCHUL, 2017a, n.p).

\section{Elementos técnicos reverberando Laban}

As relações tecidas por Laban entre o movimento, seus fatores fundantes e as forças físicas que o atravessam, especialmente a gravidade, foram sementes lançadas ao longo de sua filiação. Elas chegam em Schul através das experiências formativas que ela mesmo teve, dos estudos que empreendeu e dos ecos retransmitidos por suas mestras. Como exemplos práticos de movimentos que Schul ensina em suas aulas e que dão corpo a essa rede plural de influências e encontros, trazemos a seguir alguns exercícios técnicos que se configuram como referências diretas às pedagogias de Hanya Holm e Irmgard Bartenieff, e por conseguinte como reverberações do legado de Laban: ecos labanianos.

A começar por Holm, destacamos o vocabulário de exercícios que são executados na posição sentada, em contato com o chão na maior parte das aulas, sendo exploradas linhas posturais variadas no tronco e membros superiores, enquanto a pelve e os membros inferiores - estejam dobrados (frogsit) ou estendidos (longsit) (figura 5) - dão estabilidade. Tal noção é muito consonante à relação pontuada por Bartenieff sobre estabilidade e mobilidade (HACKNEY, 2003), visto que no chão menos partes do corpo competem por atenção, e as extremidades inferiores podem atuar como base estável, a qual embora esteja ativa é menos solicitada em termos de amplitude de movimento.

Figura 5 - Postura sentada 'frogsit'(acima), e 'longsit' (abaixo).

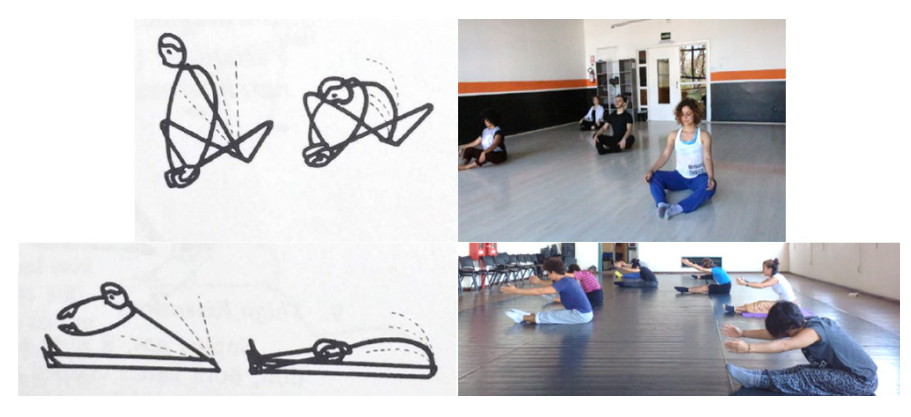

Fontes: Lockhart (1957) e Resende (2018).

Os principais movimentos contemplados nessas posturas são: enrolamento e desenrolamento da coluna vertebral (figura $6)$, volumes e vetores no tronco a partir de linhas curvas e retas, respectivamente (figura 7). 
Figura 6 - Enrolamento e desenrolamento da coluna vertebral.

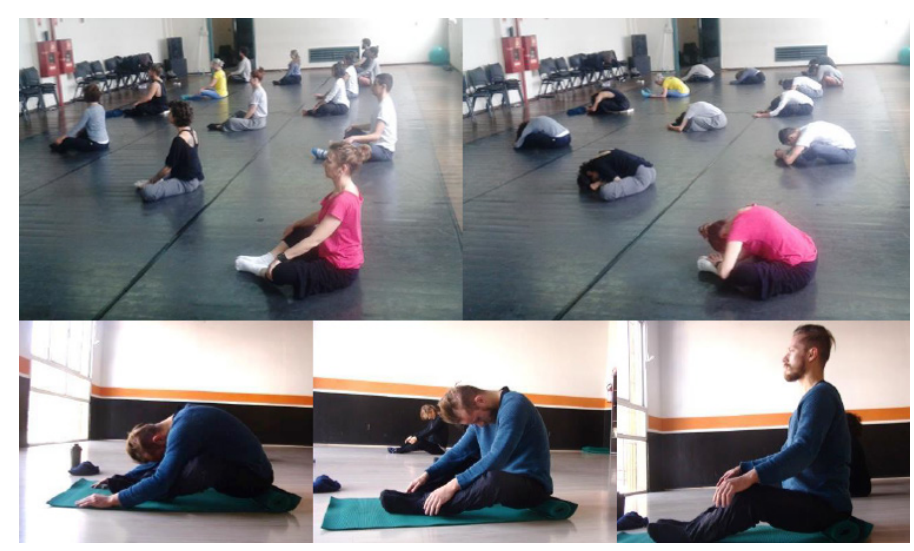

Fonte: Resende (2018).

Os movimentos trazidos na figura acima, já há bastante tempo nas aulas de Schul, tornaram-se parte de sua assinatura e habitam as memórias de muitos de seus bailarinos. Eles são conduzidos com a voz de Schul ao fundo e ao vivo, ditando a contagem e dirigindo o movimento: "Enrola um, dois, três até a cintura...e desce um, dois, três lá pro pé...voltando um, dois, três até a cintura, e alonga, dois, três, subiu". Neles observamos a diretriz de segmentação da coluna vertebral, na qual os bailarinos movem vértebra por vértebra, enrolando a coluna e descendo a cabeça até a altura da pelve, por exemplo, ou desenrolando, voltando a cabeça até a posição vertical.

Os desenhos trazidos nas figuras 7, 8, $9 \mathrm{e}$ 17 fazem parte do trabalho acadêmico desenvolvido em 1988 por Isabele Pereira ${ }^{8}$, na época aluna de Eva Schul no curso de Dança da PUC-PR, sobre a técnica Hanya Holm de dança moderna.
Figura 7 - Postura de meio-split (1/2 split) com exploração de volumes e vetores.

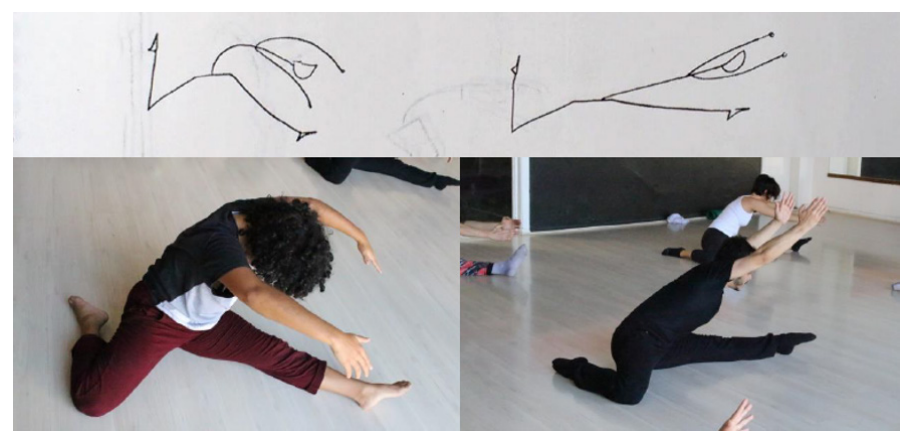

Fonte: Resende (2018).

Como mais um rastro técnico da dança moderna, a troca com o solo e a relação com o espaço e suas forças, em especial a da gravidade, são aspectos muito relevantes e estimulados durante as aulas de Schul, sobre os quais ela relata:

Uma das coisas que eu sempre gostei nesse chão é que ele começa nos pequenos grupos musculares e ele trabalha o corpo inteiro, não tem um lugar que não aquece, não tem um músculo que tu não mexe. Então, ele é muito completo. (SCHUL, 2017a, n.p).

Alguns movimentos são conduzidos na postura deitada, de forma que linhas retas verticais ou diagonais em oposição (com torções no tronco e pelve) sejam formadas na massa do ar.
8 Este material de desenhos de Isabele Pereira faz parte dos documentos que compõem o projeto Carne Digital: Arquivo Eva Schul. 
Figura 8 - Postura deitada com exploração de linhas retas verticais ou diagonais em oposição.

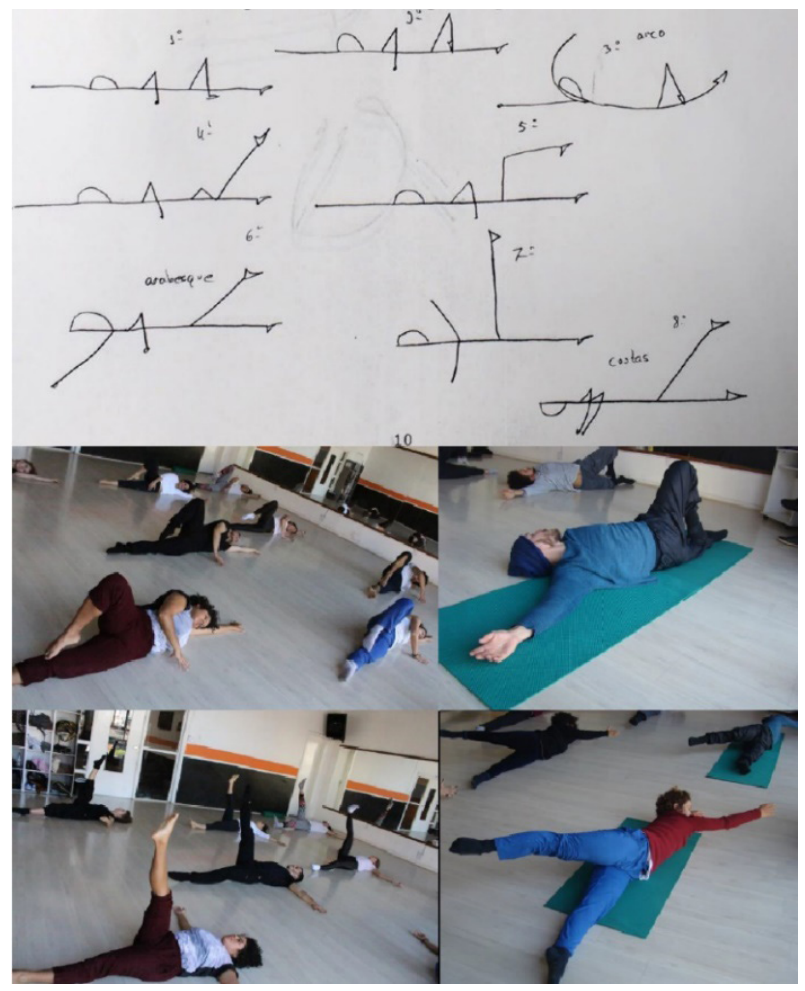

Fonte: Resende (2018).

Outro conjunto de elementos importantes, oriundo da técnica de Holm, é a sequência das 6 posições básicas. Na figura 9 vemos o desenho representativo das seis referidas posturas, em paralelo a registros fotográficos de aulas de Schul.

Figura 9 - 6 posições básicas.

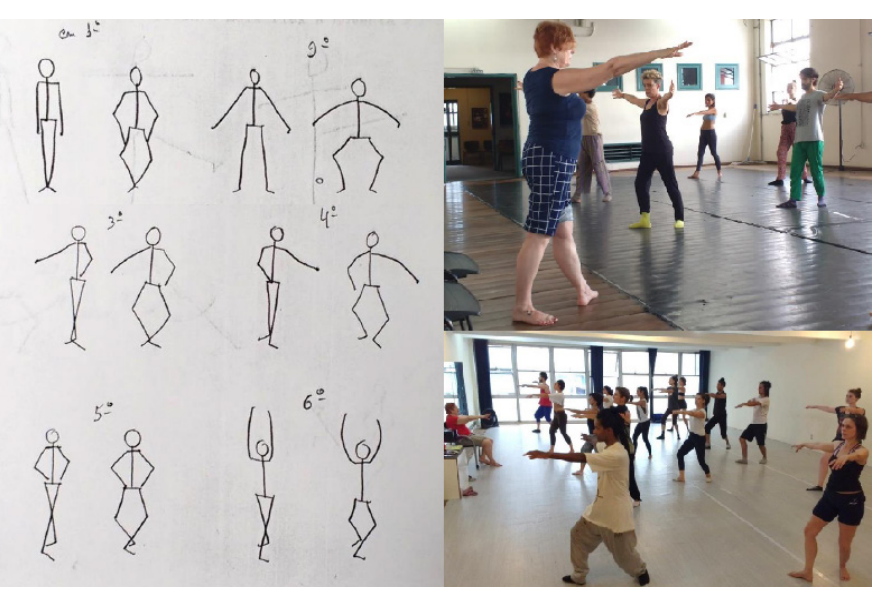

Fonte: Resende (2018).
As seis posições são praticadas com o conceito de bounce (balanço): quiques ou oscilações pra cima e pra baixo, enfatizando uma qualidade de movimento macia/ mais articular, e não tônica/mais muscular. Esses rebotes são ferramentas importantes para que cada corpo sinta e ajuste a gestão do peso na alternância entre flexão e extensão dos joelhos em cada posição.

Como um último elemento a ser situado no vocabulário apreendido em Holm, apontamos os movimentos pendulares ${ }^{9}$, swings, tanto a partir dos quadris/pernas (figura 10) quanto dos ombros/braços (figura 11).

Acontecendo nos segmentos mais periféricos e móveis do corpo, isto é, nos membros superiores e inferiores, os pêndulos designam no geral a qualidade de mover-se indo e vindo de um ponto a outro, realizando uma trajetória oscilante em torno de um eixo. Tal dinâmica geralmente envolve um segmento que é a base, um ponto fixo (ou menos móvel), e outro (ou outros) que desenha uma meia-lua numa trajetória pendular/oscilante.

Por ocorrerem mais na periferia do corpo, geralmente a partir dos membros superiores e inferiores, os movimentos pendulares devem ser respaldados por um centro (musculatura central e profunda do corpo) forte e ativo, noção que flerta diretamente com a concepção de suporte muscular interno, um dos Princípios de Movimento de Bartenieff, como veremos.

Figura 10 - Swing de quadris.

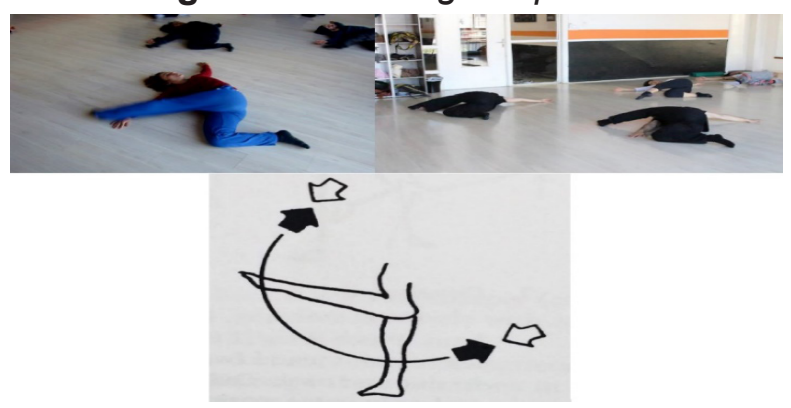

Fontes: Resende (2018), Resende; Silva (2019) e Nikolais; Louis (2005).

9 Sobre princípios organizativos de movimento presentes nas aulas de dança contemporânea de Eva Schul que envolvem diretamente este tipo de movimentação, ver: Resende (2018) e Resende; Silva (2019). 
Figura 11 - Swing de braços.

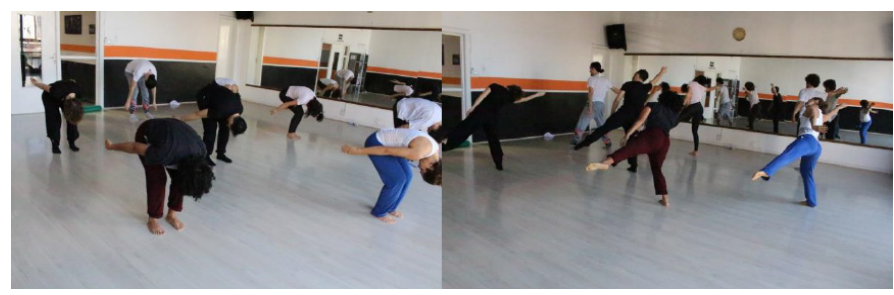

Fontes: Resende (2018) e Resende; Silva (2019).

A fisicalidade e potência muscular de movimentos foram, por muito tempo, um forte traço técnico nas aulas de Eva Schul. Depois de seu contato com a pedagogia de Bartenieff alguns segmentos dessas aulas foram reforçados com contornos deliberadamente mais somáticos, sendo estimulada nos alunos uma gestão mais explícita de economia de energia, evitando esforços desnecessários, e otimizando prospectivamente a sobrevida funcional do corpo dançante, haja vista a condução mais inteligente de suas demandas.

Essa herança de uso do chão, presente nas raízes modernas da dança, se assemelha às proposições de Bartenieff, as quais levam o corpo pra perto do solo, em atividades nas posturas deitada, sentada, ou ajoelhada no nível baixo (MIRANDA, 2008), permitindo inferir mais um ponto de contato e uma matriz em comum entre essas pedagogias.

Sobre os caminhos somáticos que permeiam as aulas de Schul, podem ser apontadas referências importantes, tais como Bartenieff e o movimento pós-moderno na dança. Sobre estas referências, Schul comenta:

Se tu olhar a Bartenieff já é somática, entende? [...] eu já tinha uma estrutura somática junto, então ela só foi se desenvolvendo conforme eu fui entendendo a dança pós-moder na'. Quando eu fiz tai chi chuan na Judson também me ajudou a entender muito essa questão do espaço né, da massa do espaço, de como a gente sustenta, como a gente tem que usar os esforços do Laban pra romper, pra puxar, pra empurrar. Então tudo vai tendo um sentido né. (SCHUL, 2017b, n.p).

Para seguir no contexto dos ensinamentos da mestra acima mencionada, é preciso citar os Bartenieff Fundamentals (BF), que dizem respeito à uma "abordagem corporal que propõe uma experiência senso-cinestésica e cognitiva, levando em conta a totalidade do corpo, assim como a conectividade dos movimentos" (CAETANO, 2012, p. 155). Essa abordagem é composta por duas categorias interdependentes: os Princípios de Movimento de Bartenieff, que são dez, e os Fundamentos Corporais Bartenieff, um grupo de seis exercícios básicos (e suas variações, além de exercícios preparatórios) que recebem esse nome por estarem relacionados às atividades básicas do ser humano e atuarem na reorganização de ações cotidianas como sentar, andar, levantar etc., a partir do acionamento da musculatura profunda (FERNANDES, 2010).

Dentre os dez princípios básicos elencados por Bartenieff, mencionamos três muito presentes na pedagogia de Eva Schul: o suporte muscular interno, as conexões ósseas, e as etapas homo e contralateral dos padrões de organização corporal. Quanto aos exercícios básicos, por sua vez, destacam-se como mais presentes: metade do corpo, queda de joelhos e círculo de braços.

10 A dança pós-moderna pode ser situada em linhas gerais como um movimento americano, ou escola estética, que teve início nos anos sessenta, desenvolvido por uma geração de coreógrafos filiada à Judson Memorial Church, em Nova York (DANTAS, 1999). Embora tenham tido maior atividade de 1962 a 1964, as questões levantadas pelo grupo seguiram reverberando nas décadas que se seguiram, em espaços e propostas nas quais Eva Schul transitou nos períodos em que viveu nos EUA. 
O suporte muscular interno diz respeito a uma ênfase situada na musculatura mais interna e profunda do corpo $^{10}$, cujo uso consciente provê estabilização e suporte, e consequentemente uma qualidade mais fluida de movimento, tendo em vista que "o uso da musculatura profunda dentro de sua funcionalidade garante a liberação dos músculos superficiais que geralmente são utilizados inadequadamente" (CAETANO, 2012. p. 160). A figura 12 apresenta bem a aplicação dessa noção em alguns movimentos, com destaque para uma amplitude mais livre das partes periféricas do corpo, asseguradas pelo centro firme e ativo.

Figura 12 - Exemplos de exercícios que evidenciam o suporte muscular interno.

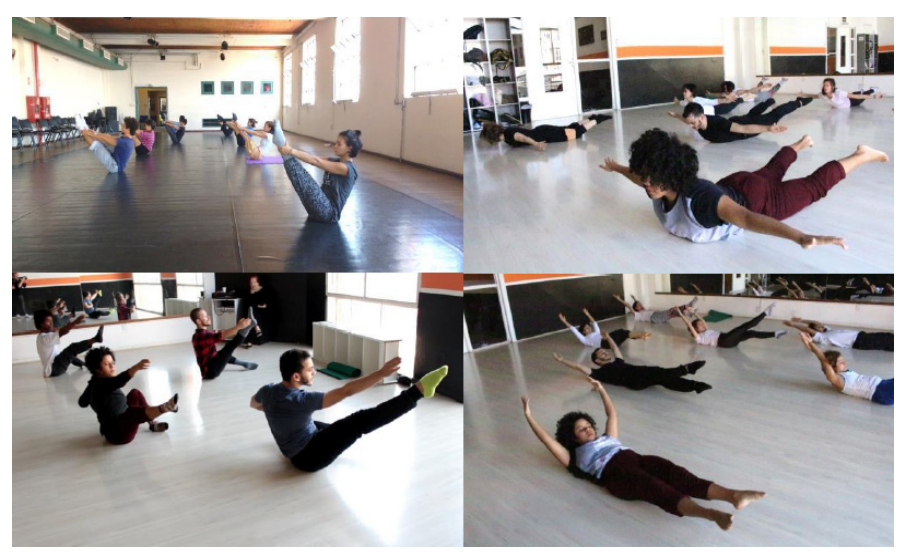

Fonte: Resende (2018).

A qualidade fluida dos movimentos (tão cara à pedagogia de Schul), respaldada por um bom suporte muscular interno, é trabalhada em sua técnica a partir de diretrizes que prezam um fluxo livre, ou não interrompido, de forma que exista o máximo possível de continuidade entre os movimentos (SOARES, 2014).

$11 \mathrm{O}$ centro do corpo, também referenciado em algumas literaturas como core, powerhouse, ou simplesmente musculatura central, trata-se de um grupo composto por musculaturas estabilizadoras, localizadas de maneira geral em plano mais profundo no corpo, estando equivalentes ao local onde se situa o centro de gravidade - isto é, aproximadamente no centro da pelve, à frente do osso sacro, na base da coluna vertebral.
$\mathrm{Na}$ pesquisa de Bartenieff a respeito da fluidez dos movimentos, a mestra destaca a existência de "conexões ao longo de sequências de músculos e caminhos diagonais do corpo" (CAETANO, 2015, p. 208), indicando como uma das estratégias para conquista da fluidez, o alinhamento dinâmico que se alcança por meio das conexões ósseas.

De todas as conexões ósseas elaboradas por Bartenieff, com exercícios em que o alinhamento corporal se baseia em referências dos ossos, destacamos duas que mais se experimenta nas aulas de Schul: a cabeça-cauda (presente inclusive em movimentos de enrolamento e desenrolamento da coluna vertebral - figura 6), e cauda-calcanhares (figura 13), com linhas imaginárias que conectam os ísquios (ossos da parte mais baixa da pelve, onde nos apoiamos pra sentar) e os calcanhares (ossos mais posteriores e inferiores do nosso pé, onde descarregamos primeiro o peso numa pisada), orientando portanto os trajetos por onde o corpo deve passar (CAETANO, 2012). Os movimentos que mais se pautam nessa conexão óssea cauda-calcanhares são: queda de joelhos (figura 13), e o círculo de braços (figura 14), ambos integrantes dos 6 exercícios básicos de Bartenieff.

Figura 13 - Queda de joelhos.

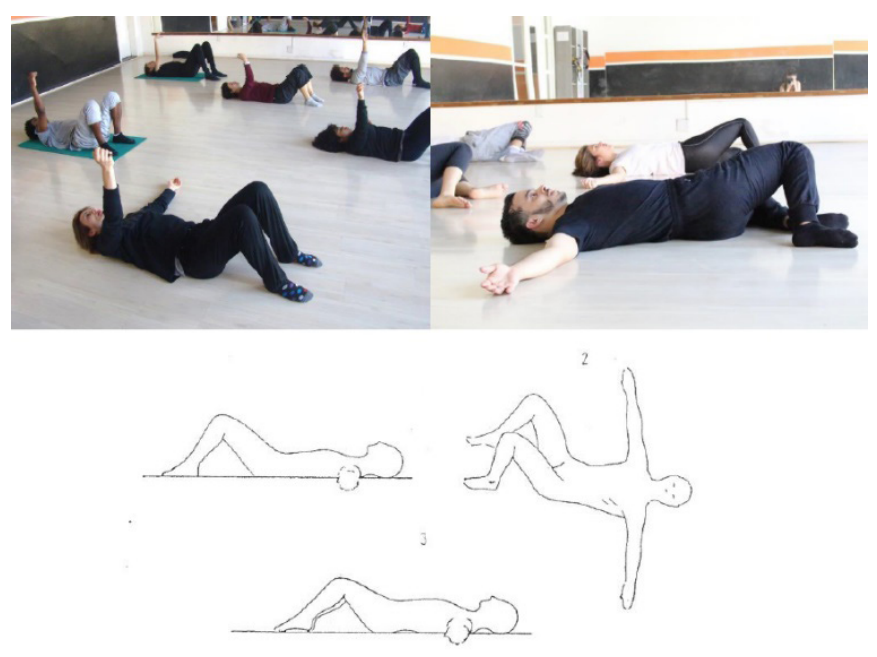

Fontes: Resende (2018); e Bartenieff; Lewis (1980). 
Figura 14 - Círculo de braços.
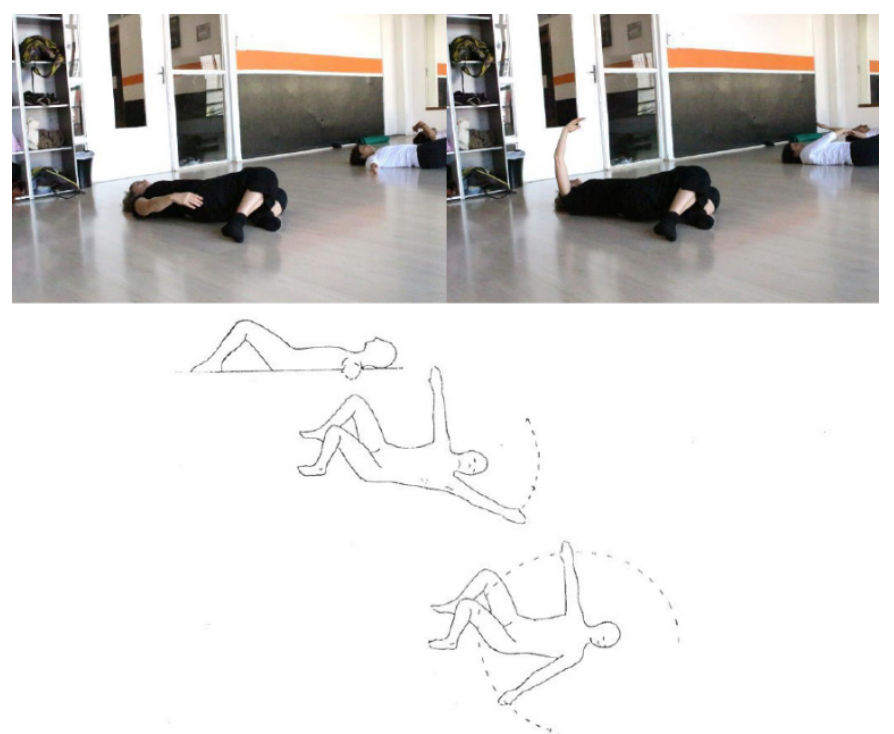

Fontes: Resende (2018); e Bartenieff; Lewis (1980).

O exercício de círculo de braços é guiado pela visualidade de um percurso arredondado que o membro superior desenha espacialmente, estando a mão do membro que se movimenta situada o mais perifericamente possível.

Quanto aos padrões de organização corporal (seis ao todo), destacamos a etapa homolateral (ou metade do corpo, consonante ao exercício básico de mesmo nome) e a etapa contralateral, também denominada lados cruzados. Tais padrões guardam relação com o "desenvolvimento e organização corporal do sistema neuro-motor que ocorrem por meio de um processo não-linear rumo à complexidade" (CAETANO, 2012, p. 161).

A etapa homolateral pode ser exemplificada através do exercício do relógio (figura $15)$, onde os membros inferior e superior de um mesmo lado se aproximam gerando rolamento do corpo para a direita ou para a esquerda.
Figura 15 - Etapa homolateral e exercício básico Metade do Corpo aplicados no Relógio.

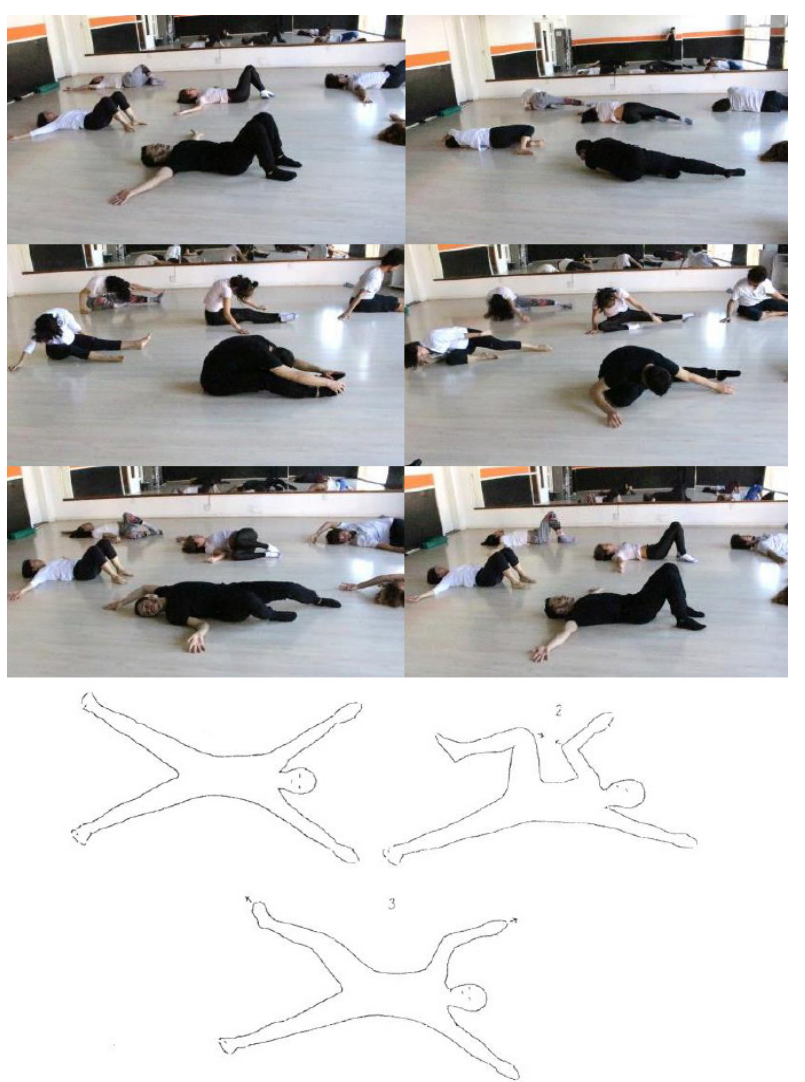

Fontes: Resende (2018); e Bartenieff; Lewis (1980).

A etapa contralateral por sua vez, também muito útil para deslocamentos rasteiros $\mathrm{e}$ progressivamente para sequências mais complexas com troca de níveis, é contemplada com muita ênfase no exercício $X$-rol/ ${ }^{11}$ (figura 16 ).

11 O centro do corpo, também referenciado em algumas literaturas como core, powerhouse, ou simplesmente musculatura central, trata-se de um grupo composto por musculaturas estabilizadoras, localizadas de maneira geral em plano mais profundo no corpo, estando equivalentes ao local onde se situa o centro de gravidade - isto é, aproximadamente no centro da pelve, à frente do osso sacro, na base da coluna vertebral. 
Figura 16 - Etapa contralateral aplicada no exercício X-roll.

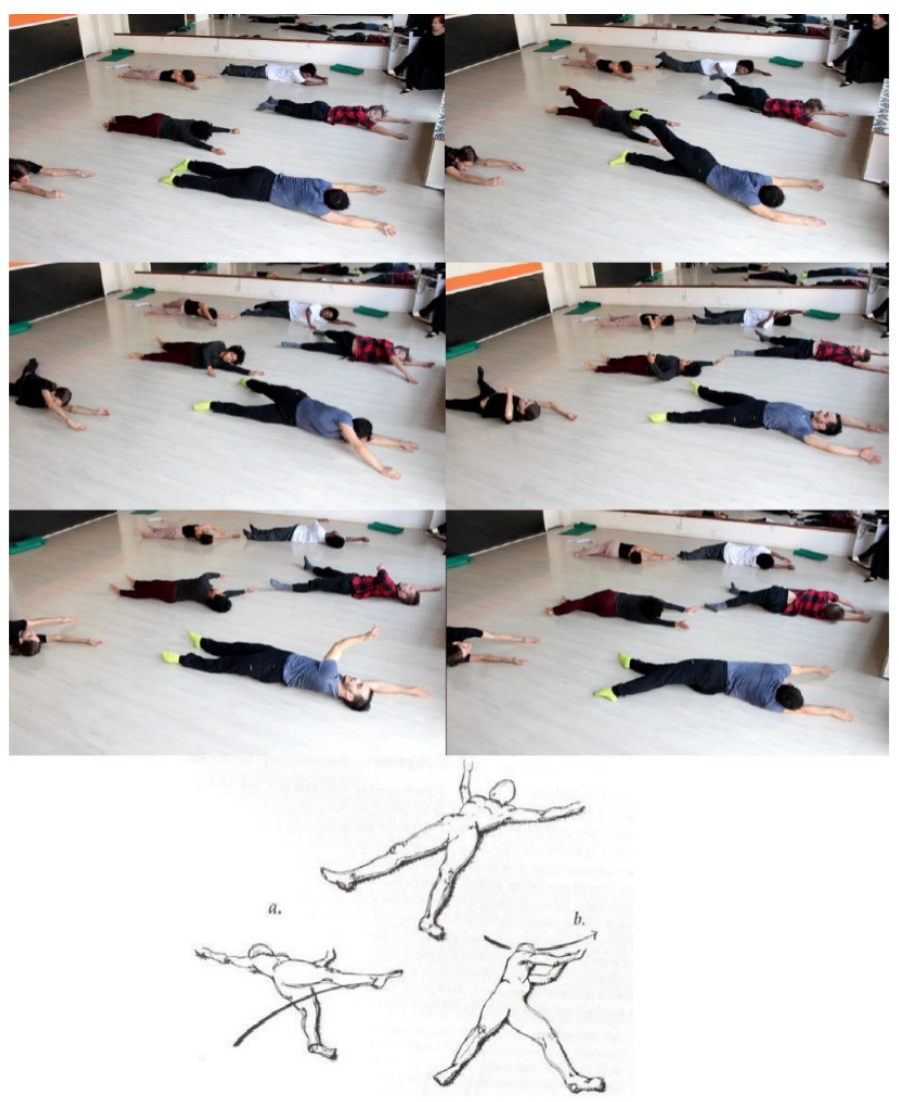

Fontes: Resende (2018); Resende; Silva (2019) e Hackney (2003).

O exercício do $X$-roll é um deslocamento rasteiro, guiado ora pela mão, ora pelo pé, para que por meio de uma torção no tronco com oposição de membros superior e inferior, o corpo vá rolando pelo solo. Ele contempla um importante princípio abordado nas aulas de Schul, o estudo do esforço mínimo, ou não esforço (DANTAS, 2012), formando junto ao fluxo o cerne da técnica de Schul. Com ele preza-se uma gestão inteligente e econômica dos esforços, sem ativação de musculaturas desnecessárias à realização de um movimento, não devendo ser equivocadamente entendido como a não necessidade de esforço.

Menciona-se por fim o exercício de propulsão da pelve (figura 17), comum às práticas de Holm e Bartenieff, e atualizada nas aulas de Schul, sugerindo uma poética de citação, de uma mestra à outra. Neste exercício os bailarinos projetam a pelve pra cima, no sentido superior, e depois para trás, em direção aos calcanhares num impulso orientado por essa linha imaginária. Apoiando-se nas mãos e nos pés, a pelve é lançada para o teto, e no movimento de retorno da pelve adota-se a posição sentada com os membros inferiores paralelos e alongados (longsit).

Figura 17 - Propulsão de pelve.

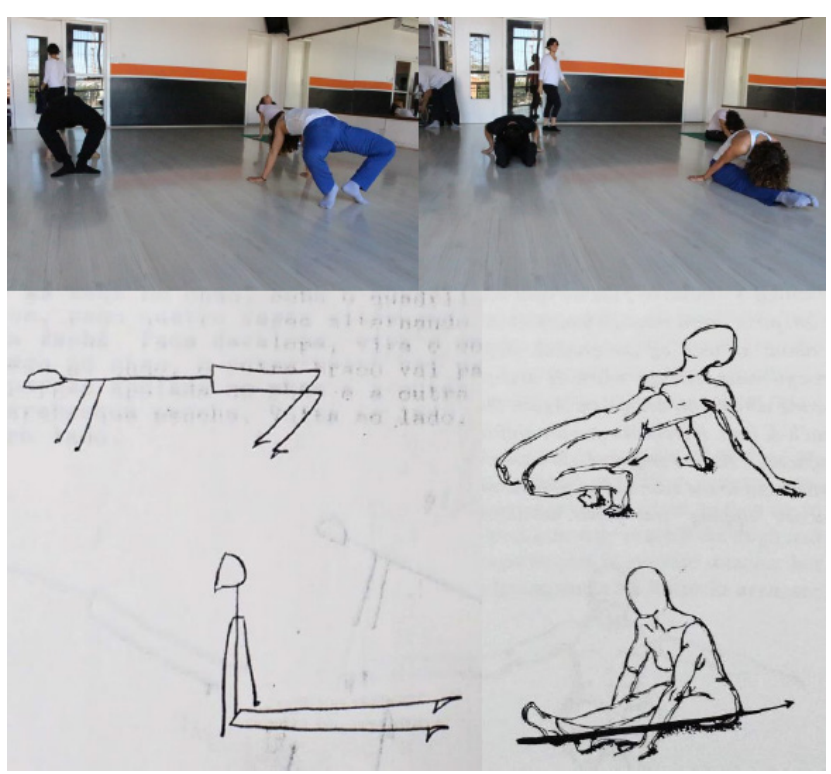

Fontes: Resende (2018); e Hackney (2003).

\section{Atualizações em devir}

O legado labaniano foi, como vimos, constantemente reelaborado, difundido e editado por discípulos e colaboradores em maior ou menor proximidade geográfica, geracional e pedagógica à figura que inspira esse dossiê de artigos. Hoje partindo de uma técnica própria, Eva Schul ecoa Laban por intermédio de suas mestras Holm e Bartenieff, reverberando suas influências, mas também amalgamando sua assinatura: ritmo, voz, escolhas e estruturas singulares.

Projetadas através de planos e dimensões tridimensionais, as proposições espiraladas de Schul evocam uma gama de qualidades do movimento, ativando diferentes esforços e respostas. A plasticidade do corpo trabalhada em suas aulas nos remete e atualiza, através de uma iconografia de desenhos e imagens, figuras e construções geométricas de La- 
ban. Estudo de forças e de energias, as quais nas palavras de Schul correspondem a uma investigação contínua de leis da física, aplicadas através da prática e vividas na poética do corpo em movimento.

\section{Referências}

ALMEIDA, M.V.M.D. Reflexões sobre a Labanotation. Cena, Porto Alegre, n. 22, p. 87-100, jul./out. 2017.

BARTENIEFF, I.; LEWIS, D. Body movement: Coping with the environment. Psychology Press, 1980.

CAETANO, P.D.L. O corpo intenso nas artes cênicas: procedimentos para o corpo sem órgãos a partir dos Bartenieff Fundamentals e do Body Mind Centering. 2012. Tese (Doutorado em Artes Cênicas). Escola de Teatro, Universidade Federal da Bahia, 2012.

Por uma Estética das Sensações: o corpo intenso dos Bartenieff Fundamentals e do Body-Mind Centering. Rev. Bras. Estud. Presença, Porto Alegre, v. 5, n. 1, 2015.

CAVRELL, H.E. Dando corpo à história. Curitiba: Editora Prismas, 2015.

DANTAS, M.F. Dança: o enigma do movimento. Porto Alegre: Ed. Universidade/ UFRGS, 1999.

Desejos de memória: procedimentos de recriação de coreografias de Eva Schul. Cena. Porto Alegre, v. 2, n. 11, 2012.

Eva Schul: uma vida para reinventar a dança moderna e contemporânea. In: SÃO PAULO. SECRETARIA DE CULTURA. Figuras da Dança: Eva Schul. São Paulo: Governo do Estado de SP, 2013.
DANTAS, M.F.; WEBER, S. O Estudo do Gesto na Encruzilhada das Práticas e Conceitos: apontamentos para a reflexão sobre encontros de pesquisadores franco-brasileiros nos Colóquios Artes do Gesto. Cena, Porto Alegre, n. 22, p. 324-338, jul./out. 2017.

ENCYCLOPEDIA OF WORLD BIOGRAPHY. Hanya Holm. The Gale Group Inc.: 2010. Disponível em: <https://biography.yourdictionary.com/hanya-holm>. Acesso em: 02 ago. 2017.

FERNANDES, C. O corpo em movimento: o sistema Laban/Bartenieff na formação e pesquisa em artes cênicas. $2^{a}$ edição: Annablume, 2006.

. Criatividade, Conexão e Integração: uma introdução à obra de Irmgard Bartenieff. In: BOLSANELLO, D. Em Pleno Corpo: educação somática, movimento e saúde. Curitiba: Juruá, 2010.

GIGUERE, M. Dança moderna: fundamentos e técnicas. Barueri, SP: Manole, 2016.

HACKNEY, P. Making connections: Total body integration through Bartenieff fundamentals. 5th edition. Routledge, 2003.

HELDEN, M.W.V; FREIRE, A.L.G. Anais do I Codança - Qual o futuro da dança. Porto Alegre: La Salle Gráfica Editora, 2002.

INFANTE, R. Fundamentos da Dança: "Corpo-Movimento-Dança”. Editora Unicentro, 2011.

LABAN, R.V. Domínio do movimento. São Paulo: Summus Editorial, 1978.

LAMBERT, M. M. Irmgard Bartenieff: uma herança de conectividade. Conceição/Conception. Campinas, São Paulo. v. 5, n. 2, p. 49-63, 2016. 
LOCKHART, A. S. Modern dance: Building and teaching lessons. WC Brown Company, 1957.

MAUSS, M. As técnicas corporais. In: MAUSS, M. Sociologia e Antropologia. São Paulo: EPU, 1974.

MOTA, J. Rudolf Laban, a Coreologia e os Estudos Coreológicos. Repertório: Teatro e Dança, v. 15, p. 58-70, 2012.

MIRANDA, R. Corpo-espaço: aspectos de uma geofilosofia do corpo em movimento. Rio de Janeiro: 7Letras, 2008.

NAVAS, C.; DIAS, L. Dança moderna. Secretaria Municipal de Cultura, 1992.

NEVES, N. A técnica como dispositivo de controle do corpomídia. 2010. Tese (Doutorado em Comunicação). Pontifícia Universidade Católica de São Paulo, São Paulo, 2010.

NIKOLAIS, A.; LOUIS, M. The Nikolais/Louis dance technique: a philosophy and method of modern dance. Psychology Press, 2005.

NORA, S. Frestas da Memória: a dança cênica em Caxias do Sul. Caxias do Sul: Lorigraf, 2013.

RENGEL, L. O corpo e possíveis formas de manifestação em movimento. São Paulo: Fundação para o Desenvolvimento da Educação-Diretoria de Projetos Especiais, 2004.

RESENDE, F.S. "Enrola um, dois, três até a cintura...": princípios organizativos de movimento nas aulas de dança contemporânea de Eva Schul. 2018. Dissertação (Mestrado em Artes Cênicas). Instituto de Artes, Universidade Federal do Rio Grande do Sul, Porto Alegre, 2018.
RESENDE, F.S.; SILVA, S.W.D. Princípios organizativos de movimento nas aulas de dança contemporânea de Eva Schul. Revista da FUNDARTE, Montenegro, $n^{\circ} 37$, ano 19, p.317-338, janeiro/março, 2019.

SANTOS, K. K. A. Um olhar sobre três obras. Monografia (Especialização). Curso de Pós-Graduação em Dança. Pontifícia Universidade Católica do Rio Grande do Sul, Porto Alegre, 2004.

SASTRE, C. Escritas de Si na Observação do Outro: procedimentos com LMA/BF na condução e leitura da dança em experimentos pedagógicos com improvisação. Cena, Porto Alegre, n. 22, p. 101-115, jul./ out. 2017.

SCIALOM, M. Laban Plural: arte do movimento, pesquisa e genealogia da práxis de Rudolf Laban no Brasil. Summus Editorial, 2017.

SCHUL, E. Entrevista concedida a Fellipe Santos Resende. Porto Alegre/RS, 16 de Agosto de 2017a.

SCHUL, E. Aula teórica/reflexiva dada a bailarinos convidados para compor o grupo pré-profissional da Ânima Cia de Dança. Porto Alegre/RS, 18 de Novembro de 2017b.

SFOGGIA, L.G. Corpo, análise e criação: uma abordagem indisciplinar da composição em dança através do sistema Laban/Bartenieff e da motif-description. Dissertação (Mestrado em Dança). Universidade Federal da Bahia, Salvador, 2013.

SILVA, E.R. Dança e pós-modernidade. EDUFBA, Editora da Universidade Federal da Bahia, 2005.

SOARES, A.C.M. Raqs el Jaci/Dança de Jaci: hibridação por antropofagia entre a dança do ventre e a poética de Eva Schul. 2014.(Dissertação) Mestrado em Artes Cênicas. Instituto de Artes, Universidade Federal do Rio Grande do Sul, Porto Alegre, 2014. 
SORELL, W. Hanya Holm: the biography of an artist. Wesleyan University Press, 1969.

STRAZZACAPPA, M. Educação Somática e Artes Cênicas: princípios e aplicações. São Paulo: Papirus, 2012.

TOURINHO, L.L; SILVA, E.L.D. Estudo do movimento e a preparação técnica e artística do intérprete de dança contemporânea. Artefilosofia, Ouro Preto, n.1, 2006.

VALLE, F. P.D. Análise do Movimento Corporal (caderno tecnológico, 08). 2005.

VIEIRA, M. S. Abordagens somáticas do corpo na dança. Rev. Bras. Estud. Presença, v. 5, n. 1, p. 127147, 2015.

Recebido: 25/06/2020

Aceito: 03/09/2020 Aprovado para publicação: 03/12/2020

Este é um artigo de acesso aberto distribuído sob os termos de uma Licença Crea- tive Commons Atribuição 4.0 Internacional. Disponível em: $<$ http://creative commons.org/licenses/by/4.0>.

This is an open-access article distributed under the terms of the Creative Commons Attribution License 4.0 International. Available at: $<$ http://creative commons.org/licenses/by/4.0>.

Ce texte en libre accès est placé sous licence Creative Commons Attribution 4.0 International. Disponible sur: <http://creativecommons.org/licenses/by/4.0>. 